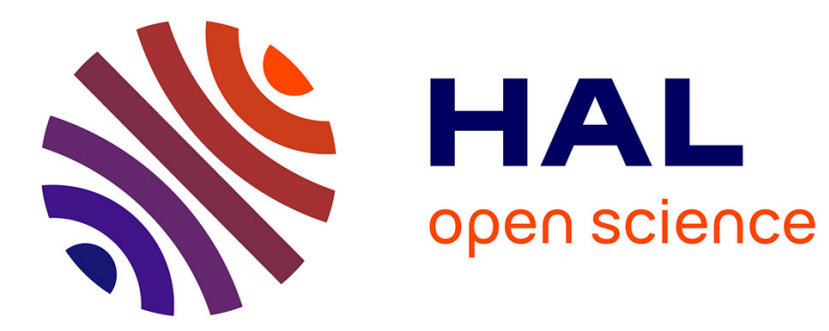

\title{
Real time in situ hard X-ray texture evolution during the annealing of rolled $\mathrm{CuNi}$ tapes
}

\author{
Antoine Girard, Pierre Bastie, Jean-Louis Soubeyroux
}

\section{To cite this version:}

Antoine Girard, Pierre Bastie, Jean-Louis Soubeyroux. Real time in situ hard X-ray texture evolution during the annealing of rolled CuNi tapes. Applied physics. A, Materials science \& processing, 2007, 90 (1), pp.179-184. 10.1007/s00339-007-4254-8 . hal-00264753

\section{HAL Id: hal-00264753 \\ https://hal.science/hal-00264753}

Submitted on 18 Mar 2008

HAL is a multi-disciplinary open access archive for the deposit and dissemination of scientific research documents, whether they are published or not. The documents may come from teaching and research institutions in France or abroad, or from public or private research centers.
L'archive ouverte pluridisciplinaire HAL, est destinée au dépôt et à la diffusion de documents scientifiques de niveau recherche, publiés ou non, émanant des établissements d'enseignement et de recherche français ou étrangers, des laboratoires publics ou privés. 


\title{
Real Time in situ hard X-ray texture evolution during the annealing of rolled CuNi tapes
}

\author{
Antoine Girard ${ }^{123}$ Pierre Bastie ${ }^{45}$ and Jean-Louis Soubeyroux ${ }^{235}$ \\ ${ }^{1}$ Systèmes et Matériaux pour la Mécatronique, Université de Savoie, France, ${ }^{2}$ \\ Consortium de Recherches pour l'Émergence de Technologies Avancées, CNRS, \\ France, ${ }^{3}$ Institut Néel, CNRS, France, ${ }^{4}$ Laboratoire de Spectrométrie Physique, \\ UJF-CNRS, France, and ${ }^{5}$ Institut Laue-Langevin, France. \\ Phone: +33 (0) 476207785 \\ Fax: +33 (0) 476635495 \\ Email: bastie@ill.fr
}

\begin{abstract}
A new real time in-situ scattering method to study texture evolution kinetic is exposed. The technique is adapted from an existing set up used at the Institut Laue-Langevin neutron facility to check monochromators. It uses a white hard $\mathrm{X}$ ray beam and works in transmission geometry. The 2D detector allows to follow recrystallization phenomena. A study of the annealing behavior of copper-nickel alloy rolled tapes, used as substrate for high temperature superconductor, is presented.
\end{abstract}

hard X-rays; diffraction; in-situ; annealing; recrystallization; CuNi 61.66.Dk / 61.10.Eq 61.18.-j / 81.05.Bx / 81.40.Ef

\section{Introduction}

In material science field it is often necessary to check crystallographic property evolution with temperature. Basic experiments could be done with ex-situ measurements, i.e. material properties are tested after a specific heat treatment. Two disadvantages can be noticed: first, the experiments are done at room temperature after cooling, which means that the samples should be quenched to reveal the crystallographic structure at high temperature. In some cases, these quenches are not possible. Secondly, to get fine evolution of the phase structure a lot of experiments are needed. An answer to this ex-situ problem is to develop real time in-situ measurements. Some common experiments are available to look for phase changes on polycrystalline material like X-ray diffraction used with a Debye-Scherrer geometry, a position-sensitive detector and an heated sample holder [1]. But this device can only reveals phase transformation of 
polycrystalline materials and is not sensitive to texture changes. In the case of a monocrystal or a not random distributed orientated polycristal, crystallographic changes versus temperature are much more difficult to analyse. Calorimetric experiments can give some information about phase transformation but are few sensitive to texture evolutions due to the small energy involved. Moreover, this can not inform about the crystallographic orientation.

The purpose of this paper is to describe an original real time in-situ experiment able to show texture evolution versus temperature of a polycrystalline tape. This experiment is adapted from an existing set-up used at the Institut LaueLangevin neutron facility of Grenoble by the monochromator group [2]. It uses hard X-ray photons which allow working in transmission through the all sample thickness, and give information of the whole sample structure [3].

To illustrate possibilities given by this new method, analysis were done on two copper-nickel alloys rolled tapes which are developed as substrate for high temperature coated superconductors. These substrates should present a biaxially textured surface to favor the epitaxial growth of upper layers, whose one of them is the superconductor ceramic (i.e. YBCO). Indeed this oxide should be well oriented to present good superconducting properties. $\mathrm{Cu}_{55} \mathrm{Ni}_{44} \mathrm{Mn}$ (known as Constantan) and $\mathrm{Cu}_{70} \mathrm{Ni}_{30}$ alloys were chosen for their cell parameters closed to the YBCO one and for their mechanical and magnetic properties [4].

\section{Experimental specifications}

A white X-ray beam issued from a $1.5 \times 1.5 \mathrm{~mm}^{2}$ focus size was used. The Philips MCN 421 X-ray generator with a tungsten anticathode may supply photons with an energy up to $420 \mathrm{kV}$. In this experiment the maximum voltage was $300 \mathrm{kV}$ with an intensity of $3 \mathrm{~mA}$. The spectrum has a continuous high energy background which corresponds to the bremsstrahlung (braking radiation) on which the two characteristic lines of the $\mathrm{W}$ tube superimpose. They are located at $59 \mathrm{keV}\left(\mathrm{K}_{\alpha}=0.21 \AA\right)$ and $67 \mathrm{keV}\left(\mathrm{K}_{\beta}=0.18 \AA\right)$, see figure 1 . The beam is collimated with a $3 \mathrm{~mm}$ diameter hole located at $3.2 \mathrm{~m}$ from the source, giving a $0.08^{\circ}$ divergent beam. 


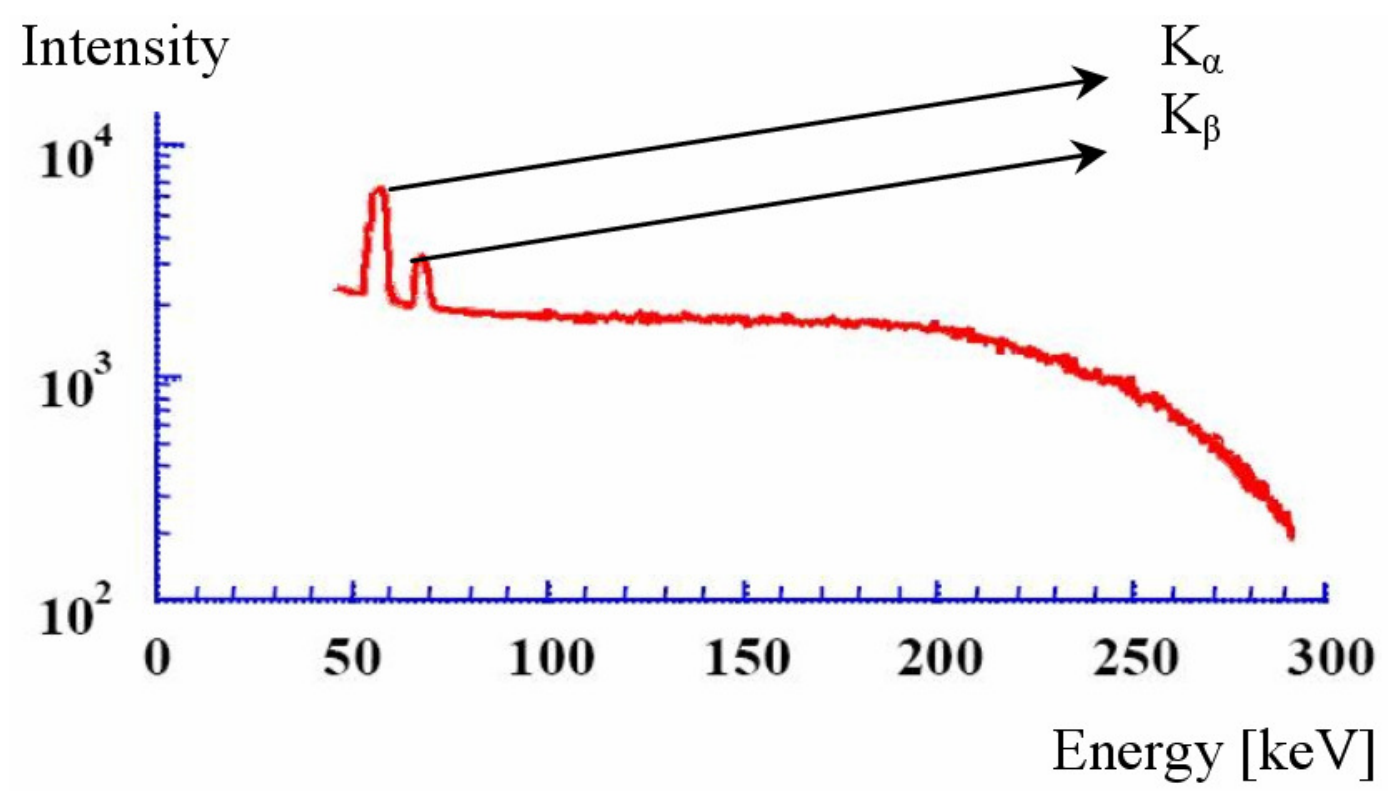

Figure 1 Energy X-ray spectrum used for experiment.

The two-dimensional detector is composed of an X-ray image intensifier with $22 \mathrm{~cm}$ diameter (Thomson TH 9428) coupled with a cooled CCD camera with weak noise (Princeton $512 \times 512$ pixels). This detector can be moved laterally and vertically to be aligned with the direct beam. The important X-ray intensity, reinforced by the focusing effect and the very high detector sensitivity, allows a short acquisition time, typically $100 \mathrm{~s}$ for one measurement. A "beam stop" aligned on the detector center attenuates the transmitted rays to avoid the saturation of the detector but also allows to follow the direct beam.

The tape was vertically applied on a sample-holder which was fixed at a stick equipped with thermocouples (figure 2). The furnace was used up to $1030^{\circ} \mathrm{C}$, with a heating rate of $5^{\circ} \mathrm{C} / \mathrm{min}$. The outer part of the furnace was cooled by a water jacket, and two silicon monocrystal windows allow the X-rays beam path. The furnace was placed on a motorized goniometer allowing an adjustment of the angular sample positioning. Vertical and horizontal shifts were ensured manually by moving the lifting truck. A turbomolecular pump ensures a $10^{-4}$ to $10^{-5} \mathrm{mbar}$ vacuum inside the furnace. 


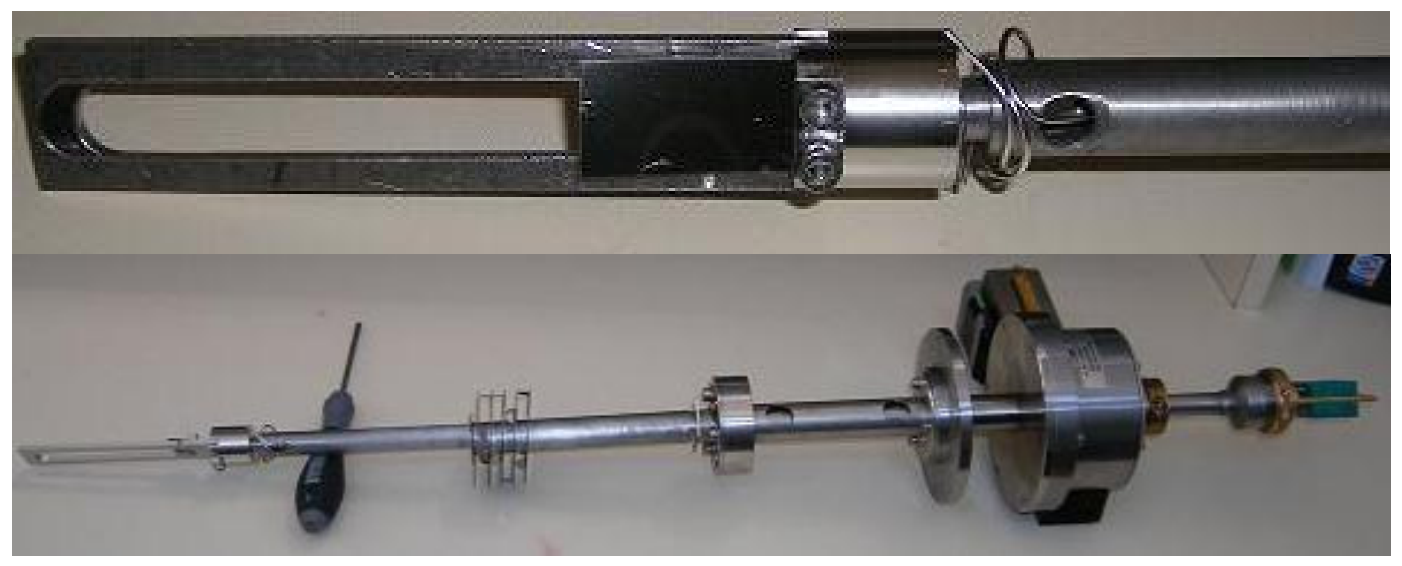

Figure 2 Sample-holder, with the sample.

Currently used to perform mosaïcity measurements on monocrystals, the line is originally built with a symmetrical ratio, i.e. the source-sample distance is equal to the sample-detector distance (usually $3.6 \mathrm{~m}$ ). With this particular condition, if the crystal is oriented with an angle satisfying the Bragg conditions, all diffracted $\mathrm{X}$-Rays are focused on a thin line [5-7]. In our case, measurements were done to follow the texture evolution in a polycristal sample. The main important fact is then to collect intensities from the two characteristic emission peaks.

When the sample is too thick to enable the overlapping of the $\mathrm{K}_{\alpha}$ and $\mathrm{K}_{\beta}$ lines, a local energy analyzer is used to separate intensities from each family plane (NaI scintillator for low energy resolution or cooled Ge diode for high resolution analysis are used). But in this study no energy detector was used as samples are $150 \mu \mathrm{m}$ thick and allowed the transmission of these characteristic $\mathrm{K}_{\alpha}$ and $\mathrm{K}_{\beta}$ lines. Considering the first interreticular distances of the alloy cells $\left(\mathrm{d}_{111}=2.06 \AA\right.$ and $\mathrm{d}_{200}=1.78 \AA$ ) and the $\mathrm{K}_{\alpha}, \mathrm{K}_{\beta}$ wavelengths, the $2 \theta$ angles are between $5^{\circ}$ and $14^{\circ}$. With a $22 \mathrm{~cm}$ detector diameter, the sample-detector distance should be smaller than $90 \mathrm{~cm}$. In this experiment a non-symmetrical transmission geometry was adopted with a $60 \mathrm{~cm}$ sample-detector distance. A picture of the assembly is shown figure 3 where all experimental devices are visible except the controlacquisition board. 


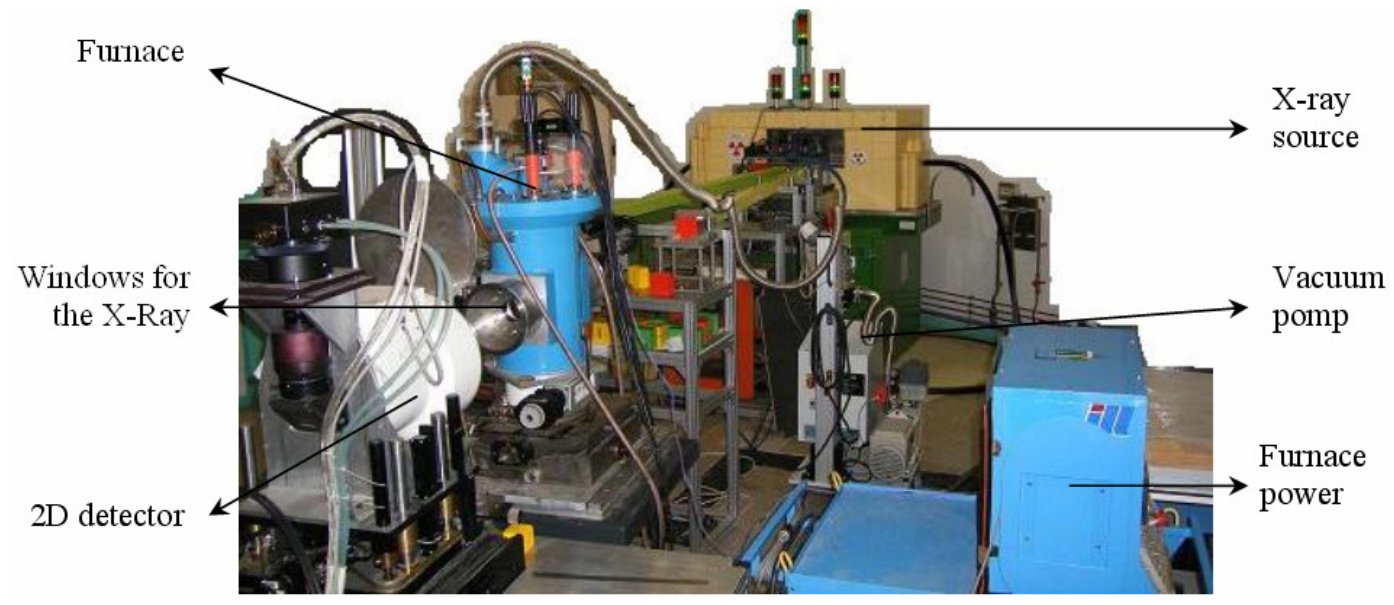

Figure 3 View of the hard X-ray scattering experimental assembly.

When the beam and the detector are aligned, a "white experiment" (without sample) is carried out (figure 4). With this diagram, intrinsic intensities of the alignment are revealed, like: absorption of the beam-stop and its holder, a more or less homogeneous background and small spots (due to the diffraction of the monocrystal silicon windows of the furnace). This background has been substrate to all experimental diffraction patterns.

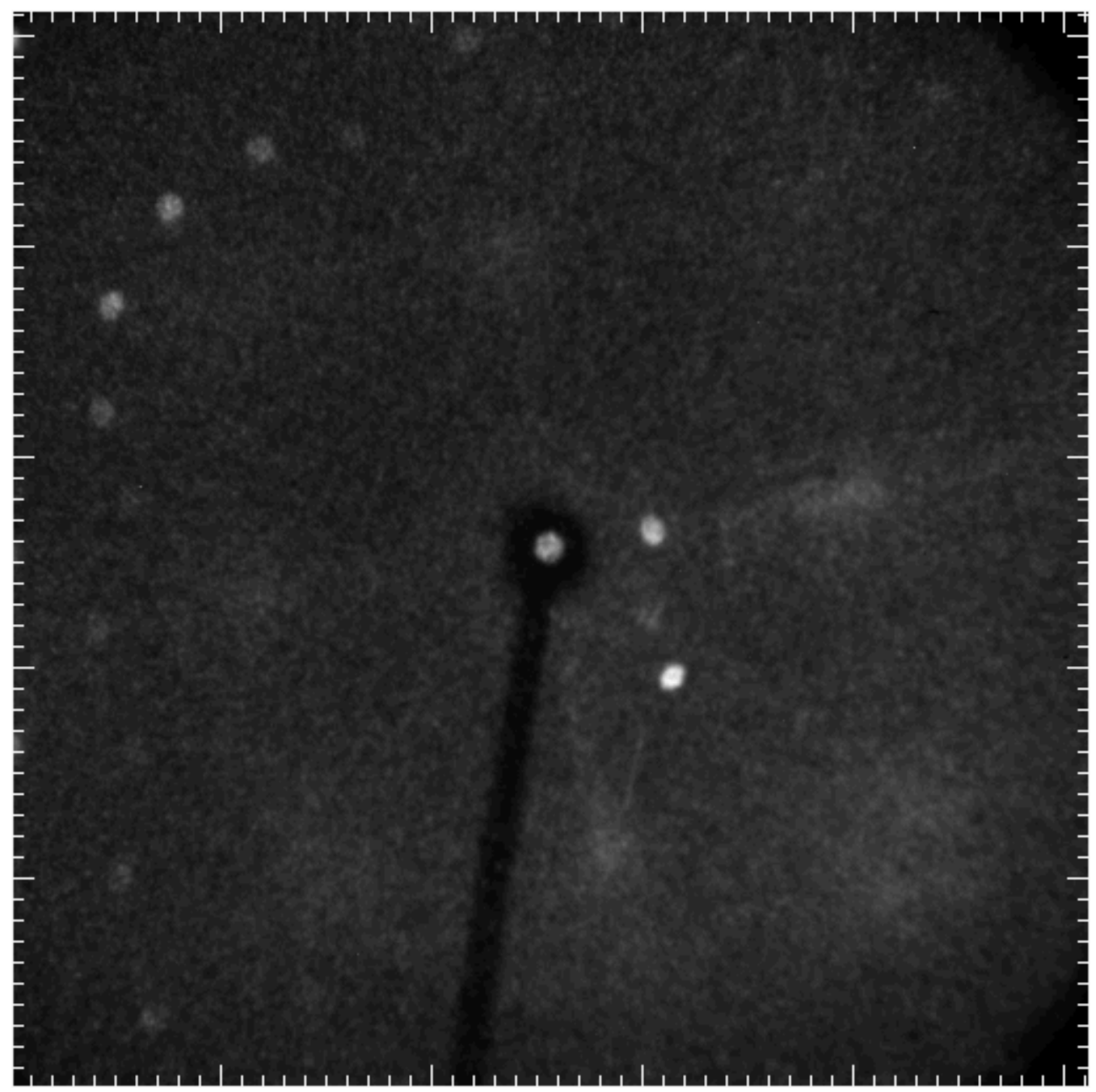


Figure 4 2D diffraction diagram without sample.

Finally, a radiographic image (i.e. using a broad beam with low intensity) is performed to ensure the good sample positioning in the X-ray beam.

All the data computations were done with the LAMP software [8].

\section{Experimental results and discussion}

2D diffraction diagrams of $\mathrm{Cu}_{70} \mathrm{Ni}_{30}$ tape are recorded each $10^{\circ} \mathrm{C}$ during the annealing $\left(5^{\circ} \mathrm{C} / \mathrm{min}\right)$. Figure 5 presents four of them. a) is the diffraction pattern at the beginning: $30^{\circ} \mathrm{C}$. That means that the tape shows the rolled structure after $98 \%$ deformation. b) and c) are respectively recorded at $610^{\circ} \mathrm{C}$ and $1000^{\circ} \mathrm{C}$ (maximum temperature of the experiment). d) is the diffraction diagram of the sample after cooling at room temperature (RT).

To better understand the diagram, figure 6 shows the theoretical diffraction circles calculated for a $\mathrm{Cu}_{70} \mathrm{Ni}_{30}$ random powder. Each circle corresponds to the diffraction of a specific wavelength with different interreticular distances. The smaller dashed circle is the theoretical position for the (111) diffraction plane by the smallest wavelength, i.e. the highest energy: $300 \mathrm{keV}$. Inside this circle no intensity from the sample can diffract. The solid circles are the scattering positions for the (111), (200) and (220) planes with $K_{\alpha}$ and $K_{\beta}$ energies. The $(111) \mathrm{K}_{\alpha}$, and the $(200) \mathrm{K}_{\beta}$ circles are very close and it is not possible to distinguish their respective contribution. Plans that have $h^{2}+k^{2}+l^{2}$ higher than 8 can not diffract in the $2 \mathrm{D}$ detector with $\mathrm{K}_{\alpha}$ and $\mathrm{K}_{\beta}$ energies. In addition to the intensities diffracted by the $\mathrm{W}$ characteristic energies, the radial streak intensities are due to the diffraction by wavelengths of the bremsstrahlung.

The use of transmission geometry and high energy radiation allowed to be sensitive to the diffraction planes which are almost parallel to the normal of the tape surface. These intensities correspond to the ones observed in the pole figure periphery. To simplify the correlation between intensities observed in figure 5 with a given orientation, theoretical pole figures of the tape are presented in figure 7. The three upper figures are the (111), (200) and (220) pole figures of a rolling tape. The represented intensities are those of a fcc metal with a "pure metal" type deformation structure. These structures are composed with 8 different orientations which are the $S=\{123\}<634>$, the $C=\{112\}<111>$, the $B=\{110\}<112>$ and their symmetric orientations. The three lower figures are the (111), (200) and 
(220) pole figures of the cubic orientation $\{100\}<001>$. This structure is the annealed texture of a tape that acquires a $\mathrm{C}+\mathrm{S}+\mathrm{B}$ structure after rolling.

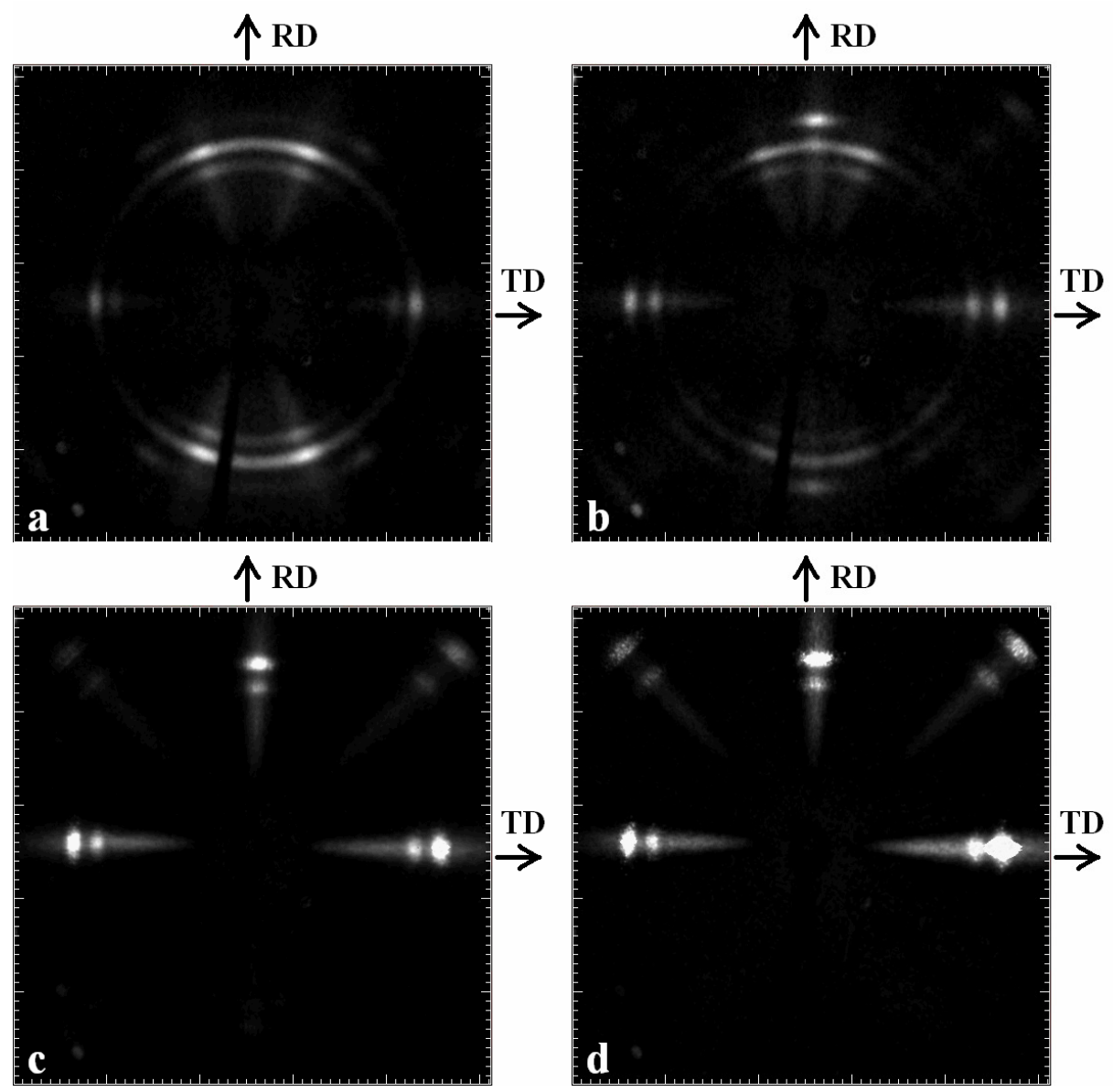

Figure $52 \mathrm{D}$ diffraction pattern of a $\mathrm{Cu}_{70} \mathrm{Ni}_{30}$ rolled tape a) not annealed, b) during the annealing process at $610^{\circ} \mathrm{C}, \mathrm{c}$ ) at $1000^{\circ} \mathrm{C}$ and d) after cooling at room temperature. 


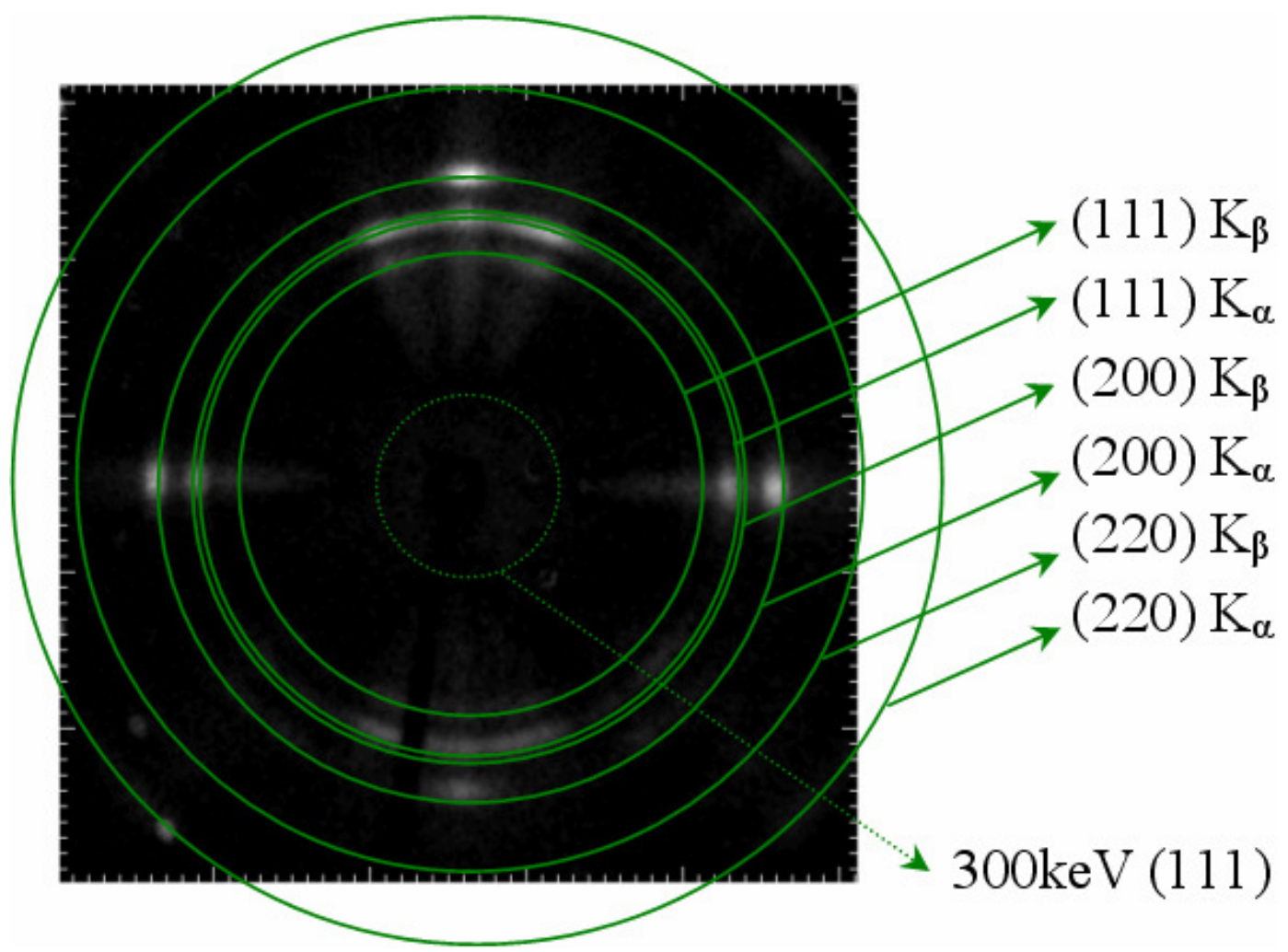

Figure 6 Theoretical diffraction circle positions for $\mathrm{a} \mathrm{Cu}_{70} \mathrm{Ni}_{30}$ random powder for different energies and different planes. The measured pattern is the same that the figure $6 \mathrm{~b}$.

On the figure $5 \mathrm{a}$ it is possible to observe all the intensities from the rolled tape diffraction pole figures periphery. For example on the transverse direction (TD) the intensities correspond to the B orientation diffraction of the (111) plane and are well located on the $(111) \mathrm{K}_{\alpha}$ and $(111) \mathrm{K}_{\beta}$ circles. Similar observations can be made at $15^{\circ}$ on each side of the rolling direction (RD) also on the (111) $\mathrm{K}_{\alpha}$ and $(111) \mathrm{K}_{\beta}$ circles and correspond to the $\mathrm{B}$ and $\mathrm{S}$ orientation diffractions of the (111) plane. The weak intensities on the $\mathrm{RD}$ on the same circles are due to the $\mathrm{C}$ orientation diffractions of the (111) plane. On the $(200) \mathrm{K}_{\alpha}$ and $(200) \mathrm{K}_{\beta}$ circles at $35^{\circ}$ on each side of the $\mathrm{RD}$, intensities are due to the $\mathrm{B}$ orientation diffractions of the (200) plane. Figure 5 are then well representative of a rolling deformation texture.

On the figure $5 c$, intensities from the cubic orientation are visible on the RD et TD if considering the $(200) \mathrm{K}_{\alpha}$ and $(200) \mathrm{K}_{\beta}$ circles and on the bisecting lines if considering the $(220) \mathrm{K}_{\alpha}$ and $(220) \mathrm{K}_{\beta}$ circles. No intensity from the $\mathrm{K}_{\alpha}$ and $\mathrm{K}_{\beta}$ energy on the $(111) \mathrm{K}_{\alpha}$ and $(111) \mathrm{K}_{\beta}$ circles can be seen, as no intensity is observed in the (111) pole figure periphery. Intensities are less important in the half lower part because the tape is probably bent slightly with the temperature as the sample is only fixed to one side with screws. 
Figure $5 \mathrm{~b}$ is recorded during annealing at $610^{\circ} \mathrm{C}$. Both textures, rolled and annealed, can be seen.

Figure $5 \mathrm{~d}$ is the diffraction pattern recorded at RT after cooling down. Intensities are in the same place than these observed on figure $5 \mathrm{c}$ but they are less spread with a higher maximum level. The difference is probably not due to structure changes but should be the consequence of a better structure of the diffusion pattern at low temperature through the Debye-Waller coefficient [9].
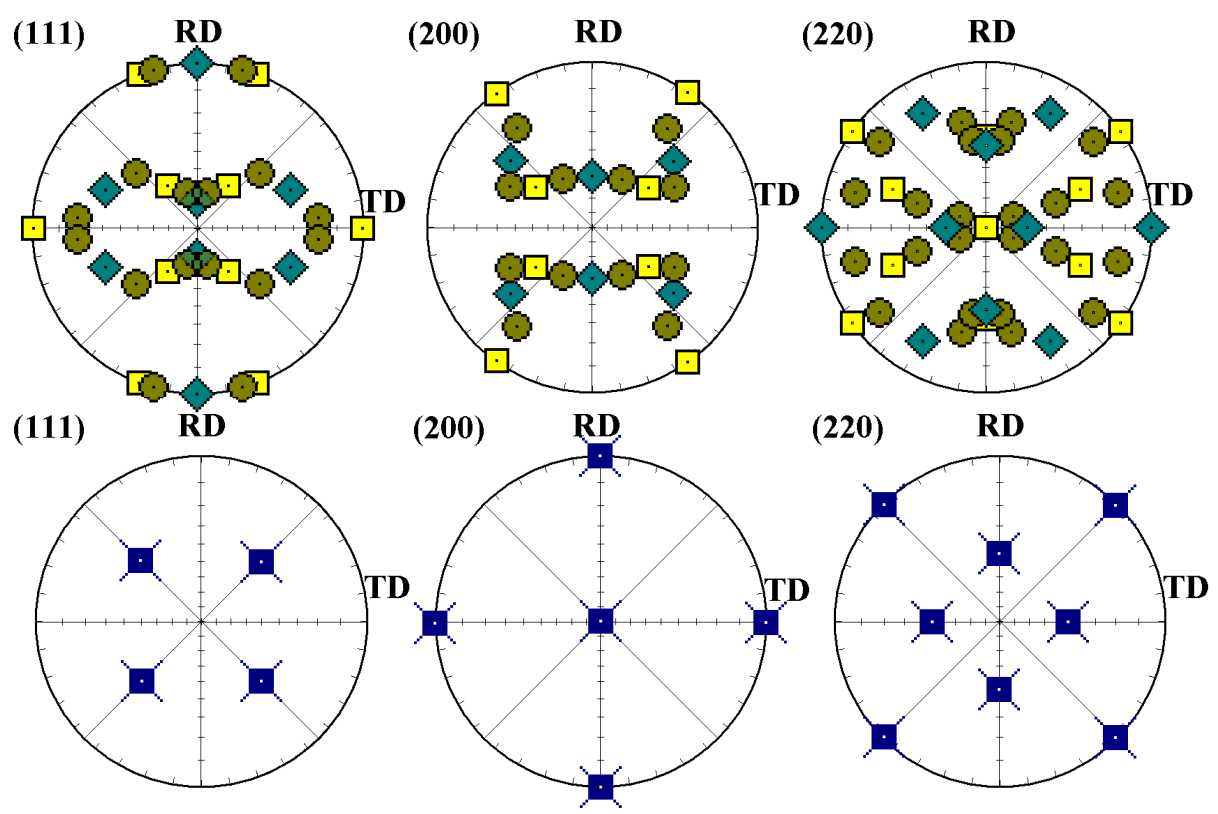

Figure 7 (111), (200), (220) pole figures with theoretical intensity localizations which can be seen on a fcc material with a "pure metal" type after a heavy rolling (up), then annealed (bottom). Marks represent specific orientations (and their equivalences) $=\mathrm{S}=\{123\}<63-4>,=\mathrm{C}=$ $\{112\}<11-1>,=\mathrm{B}=\{110\}<1-12>, \quad=$ cubic $=\{100\}<001>$

To allow a better visualization of the transition, intensities from a small horizontal stripe which goes through the centre for each recorded pattern, are plotted versus temperature (figure $8 \mathrm{a}$ ). Figure $8 \mathrm{~b}$ is the same but considering the vertical stripes. On these graphs, it is possible to follow the intensity evolutions of the $(111) \mathrm{K}_{\beta}$, $(111) \mathrm{K}_{\alpha},(200) \mathrm{K}_{\beta}$ and $(200) \mathrm{K}_{\alpha}$ lines. As in one hand the $(111) \mathrm{K}_{\beta}$ line has too small intensities and in the other hand $(111) \mathrm{K}_{\alpha}$ and $(200) \mathrm{K}_{\beta}$ lines are to close to separate their respective contribution, the better choice is to follow the $(200) \mathrm{K}_{\alpha}$ evolution. Contributions of each 4 lines are summed and plotted with temperature (figure 9, blue line). The same works have been done with a Constantan tape which has a higher nickel content: $\mathrm{Cu}_{55} \mathrm{Ni}_{44} \mathrm{Mn}$ (red line).

With these two curves, the recrystallisation kinetics can be followed. In the insert the beginning transformation temperatures may be evaluated. The intersection of 
the two tangents points out the temperatures: $582^{\circ} \mathrm{C}$ and $595^{\circ} \mathrm{C}$ for $\mathrm{Cu}_{70} \mathrm{Ni}_{30}$ and Constantan respectively. These values fit well with other measurements performed elsewhere with other diffraction techniques [10]. The small difference between these temperatures is probably due to higher nickel content of the Constantan which increases the thermic phenomena to higher temperature level.

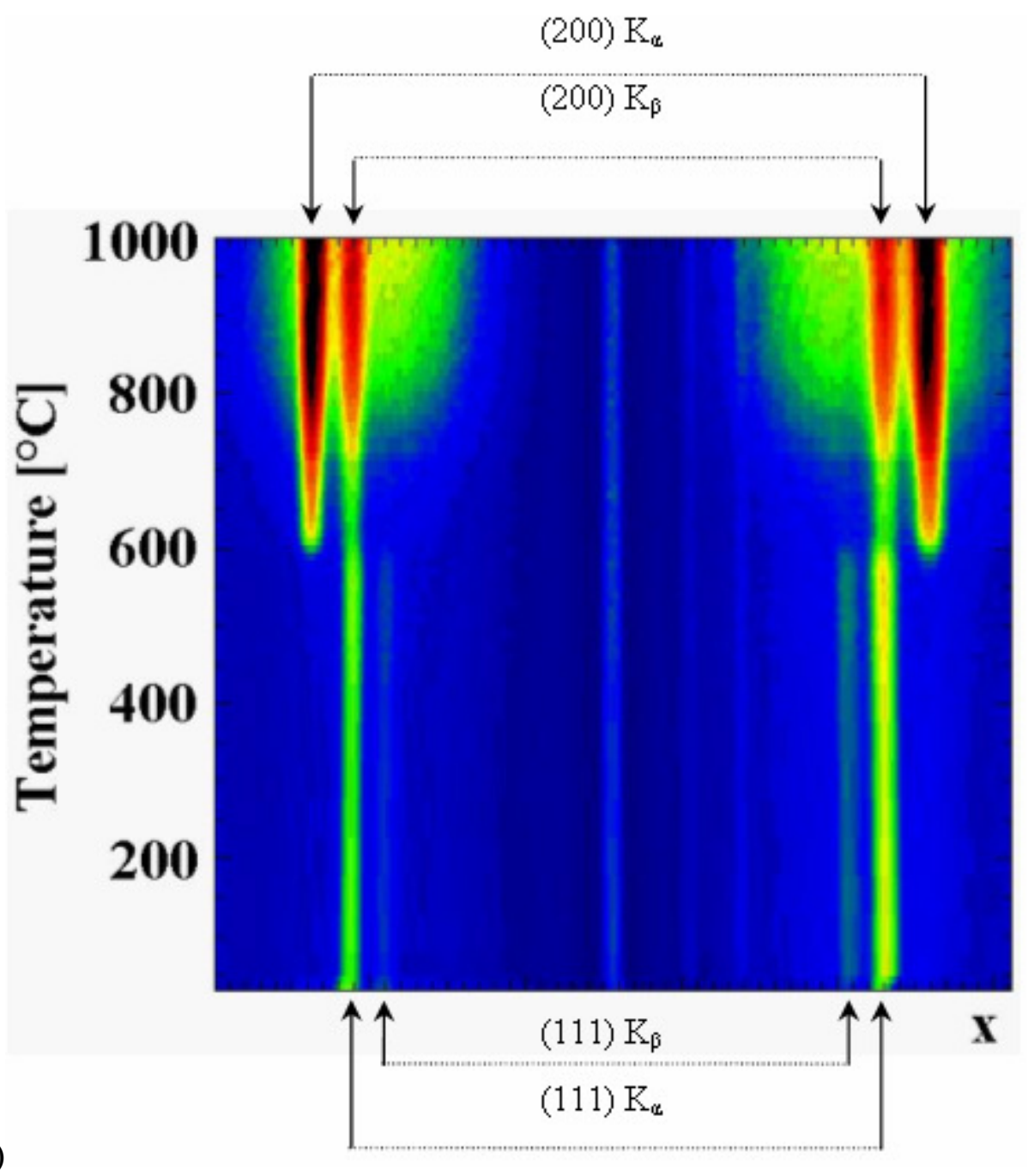




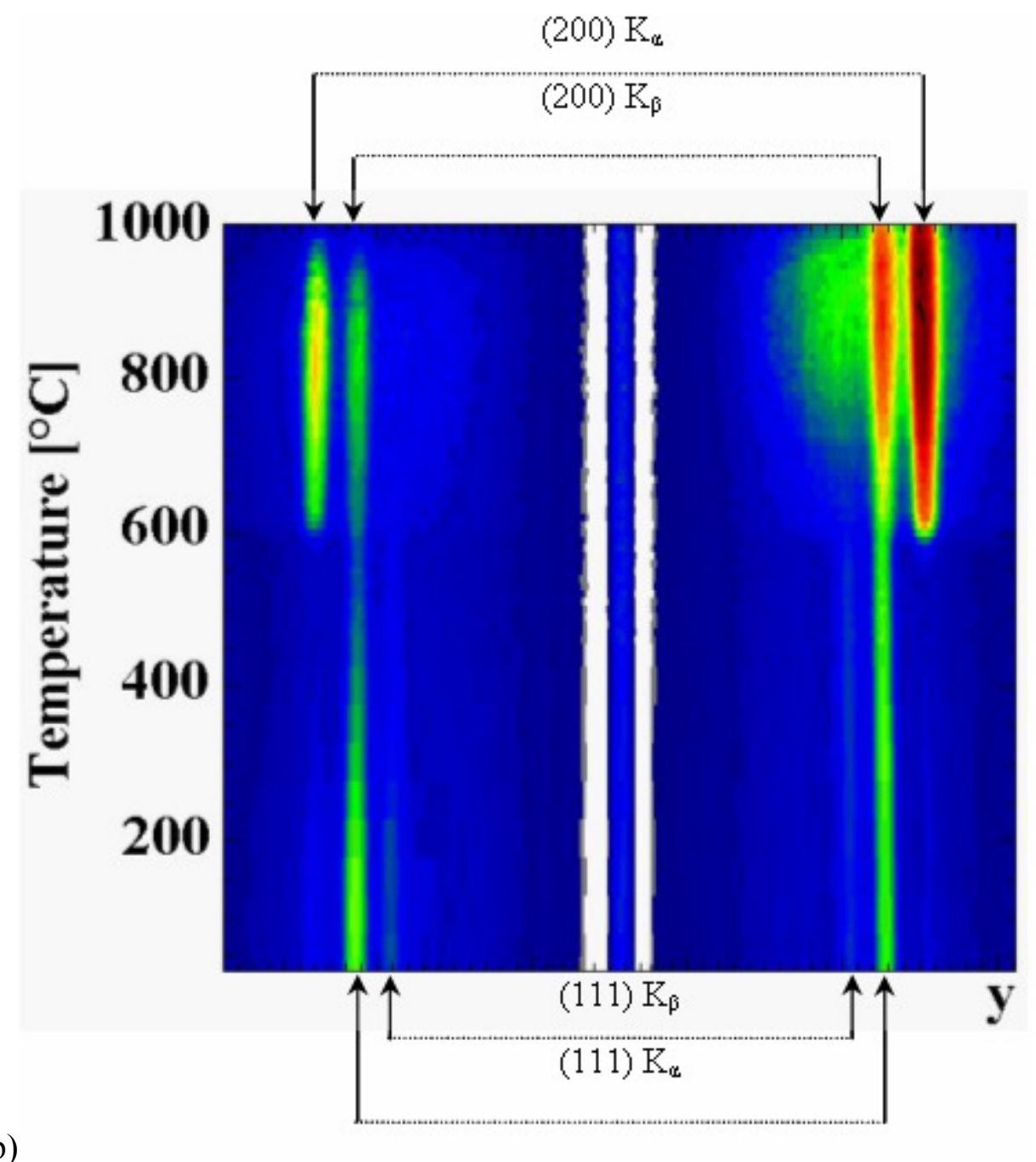

b)

Figure $8 \mathrm{TD}$ (a) and $\mathrm{RD}$ (b) cross section of each recorded scattering pattern plot versus annealing temperature.

The curves show that the transformation is very abrupt, as the half of the maximum intensity is reached in $50^{\circ} \mathrm{C}$ which is equivalent to $10 \mathrm{~min}$.

The interpretation of the transformation around the maximum (between $900^{\circ} \mathrm{C}$ and $950^{\circ} \mathrm{C}$ ) needs much more experiments to better understand the contributions to the phenomena. Indeed, in one hand biaxial texture breaks down after a critical temperature which leads the intensity to decrease, and in the other hand intensity normally decreases even for a stable crystal due to Debye-Waller coefficient. 


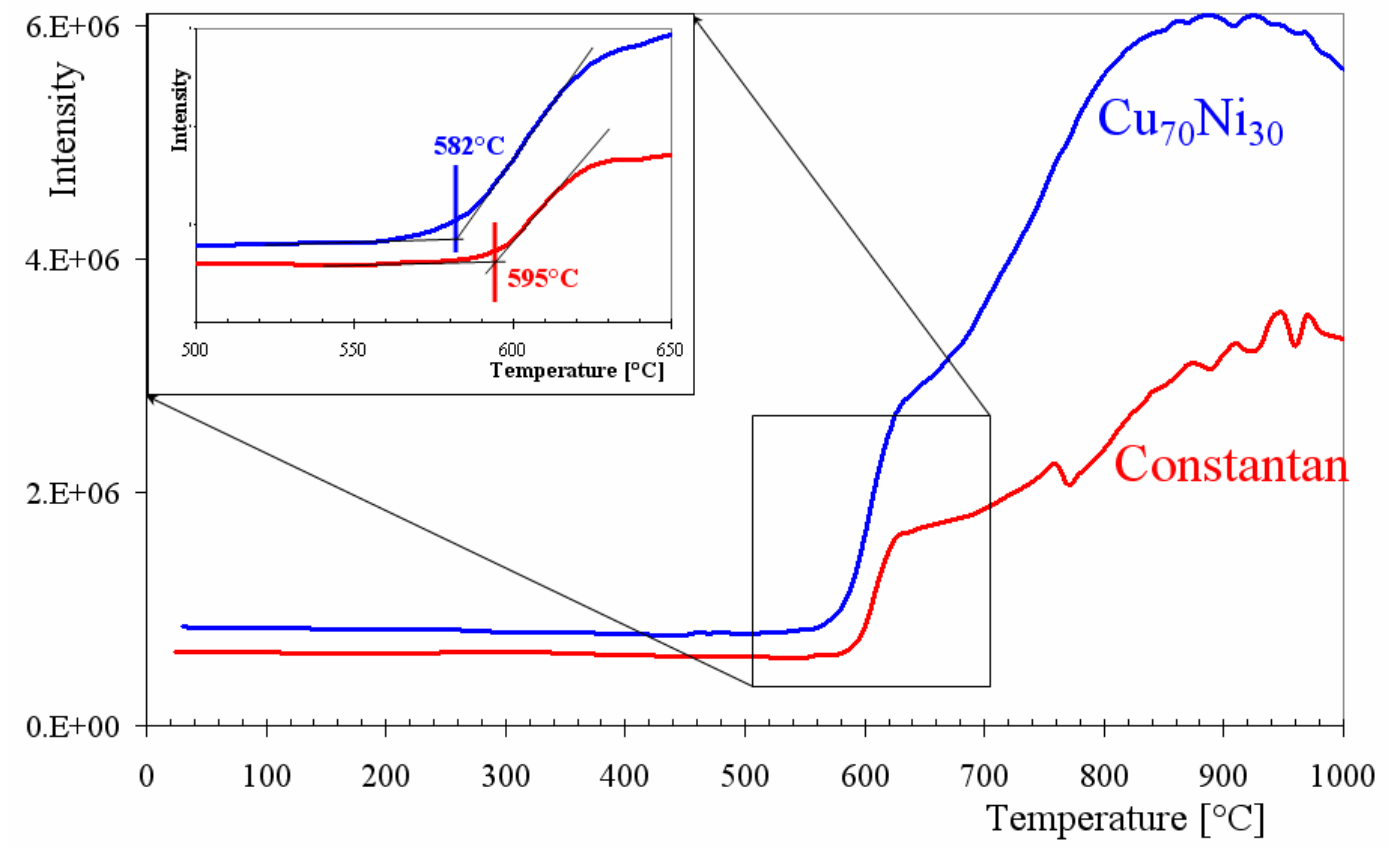

Figure 9 Sum of the 4 contributions of the (200) Ka peak is plotted with annealing temperature for both Constantan and $\mathrm{Cu}_{70} \mathrm{Ni}_{30}$ tapes.

Some quantitative informations about the sharpness of the annealed texture can also be extracted from the data. The out-of-plane disorientation, normally given by the rocking curve may be directly checked by measuring the full width half maximum (FWHM) of the $(200) \mathrm{K}_{\alpha}$ intensity distribution (perpendicularly to the radial direction). Out-of-plan disorientation in the rolling direction (RD) and in the transverse direction (TD) can be separately measured by checking respectively the intensity distribution in the RD or TD. Figure 10 shows the evolution of the intensity distribution corresponding to a rocking curve in the RD.

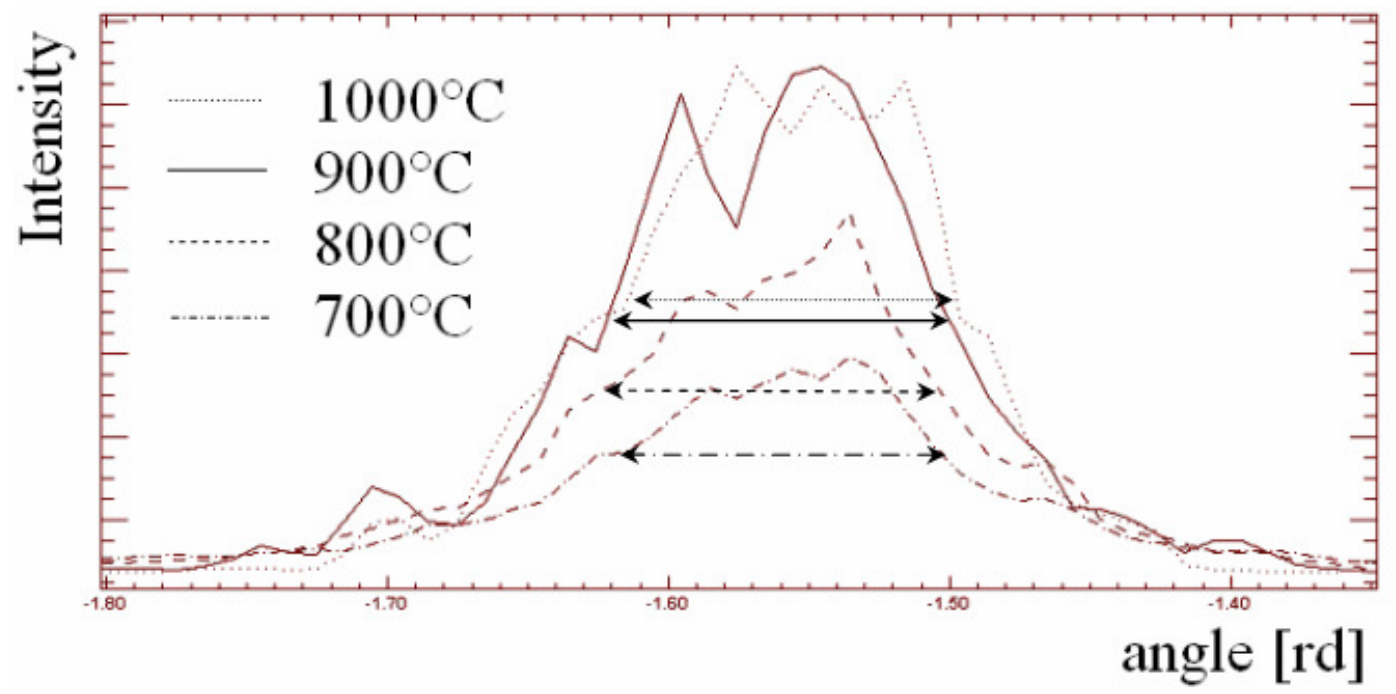

Figure $10(200) \mathrm{K}_{\alpha}$ intensity of the rolling direction recorded during the annealing of a Constantan tape. Arrows represent the FWHM of respective curves at different temperatures. 
Despite an increasing of the intensity, FWHM does not present any significant variation between $700^{\circ} \mathrm{C}$ and $1000 \mathrm{C}^{\circ}$. The out-of plan disorientation (RD) is about $7^{\circ}$ which corresponds more or less to figures find in a normal rocking curve measurement at RT on an annealed tape by X-ray pole figures.

\section{Conclusions}

This original real time in-situ hard X-ray diffraction method first developed for monocrystal measurements provides also interests for non-random polycristal studies. Indeed with this transmission geometry alignment, texture evolution could be followed in real time during heating treatments. Qualitative, as well as quantitative, results are available.

First experiments done on the annealing behaviour of copper-nickel alloys rolled tapes, have allowed to validate the method, the setting and the new dedicated furnace. Interesting biaxially textured recrystallisation kinetics data have been recorded. The beginning of the transformation has been found at $580-595^{\circ} \mathrm{C}$ depending of the nickel content. Fast evolution is then noticed before that the intensity slowly decreases after a maximum value. The interpretation of this last phenomena could be explained either by the untexturation of the material or the intrinsic decrease of the intensity with high temperature (Debye-Waller coefficient). Quantitative out-of-plan disorientation may also be checked with this method.

This real time in-situ, non destructive technique able to check texture evolution versus temperature in bulk material by using relatively cheap device is surely promising for future developments.

Acknowledgements: The authors wish to thank Mr. A. Daramsy and ILL staff for their technical assistance. This work has been carried out in the frame of the project: "Superflex" with the support of the "Région Rhône-Alpes".

References

1. P. Bénard, J.P. Auffrédic,. D. Louër: Materials Science Forum 228-231, 325 (1996)

2. B. Hamelin: Annual Report ILL 1998, 98 (1998)

3. T. Chauveau, P. Gerber, P. Bastie, B. Hamelin, J. Tarasiuk, B. Bacroix: Journal de Physique IV 12, 107 (2002)

4. A. Girard, C.E. Bruzek, J.L. Jorda, L. Ortega, J.L. Soubeyroux: Journal of Physics: Conference Series (EUCAS 2005) 43, 341 (2006) 
5. B. Hamelin, P. Bastie: Journal de Physique IV 8, 3 (1998)

6. B. Hamelin, P. Bastie: Proceeding of SPIE 2002 4786, 29 (2002)

7. B. Hamelin, P. Bastie, D. Richard, A. Elaazzouzi: Journal de Physique IV 118, 437 (2004)

8. ILL-Computing-dept LAMP the Large Array Manipulation Program:

http://www.ill.fr/data_treat/lamp/front.html

9. E.F. Kaelble: Handbook of X-rays (Mc Graw-Hill Book Company New-York 1967)

10. J.L. Soubeyroux, C.E. Bruzek, A. Girard, J.L. Jorda: IEEE Transactions on Applied Superconductivity, ASC2004 15, 2687 (2005) 